\title{
Experimentelle Studien über die Veränderungen des Eiweisses, Kohlehydrates und Blutgases im konservierten Blut.
}

\author{
I. Mitteilung. Versuch am normalen, azidotischen und \\ alkalotischen Blut.
}

Von

\section{Kazuo Owada.}

(大和明一男)

(Aus der Medizinischen Klinik von Prof. Dr. T. Kato, Tohoku Reichsuniversität zu Sendai.)

In der Klinik wird die Bluttransfusion vorwiegend mit frischem Blut vorgenommen, in der Kriegs- oder Unfallsmedizin aber kommt die Transfusion konservierten Blutes gelegentlich im Notfall zur Anwendung. Weil, ${ }^{1)}$ Rous u. Turner, ${ }^{2}$ Robertson, ${ }^{3)}$ Eljaševič u. Kazakov," Irger, Sasonkin u. Mazelev, Costa, ${ }^{5}$ Sammar tino, ${ }^{7)}$ De Blasio, ${ }^{8)}$ Aleksandrowicz, ${ }^{9)}$ Domanig, ${ }^{10)}$ Bagdassarov, ${ }^{11)}$ Wilson $u . ~ J a m i e s o n,{ }^{12)}$ Rzepecki, ${ }^{13)} H e i m^{14)}$ haben am

1) We il, Journ. Amer. Med. Assoc., 1915, 64, 425.

2) Rous u. Turner, Journ, Exp. Med., 1916, 23, 239.

3) Roberts on, British Med. Journ., 1918, 691.

4) Eljašcevic u. Kazakov, Sovrem. Probl. Gematol, i. Perelivanija Krovi 11/12, 82, 1935 (Russisch). (Ref. in Zentralorg. f. ges. Chir., 1937, 81, 274.)

5) Irger, Sasonkin u. Mazelev, Vestn. Chir., 1935, 38, 137 (Ref. in Zen. tralorg. f. ges. Chir., 1936. 76. 173). $82,678)$

6) Costa, Semana méd., 1986, 11, 783. (Ref. in Zentralorg. f. ges. Chir., 1937,

7) S a martino, Semana méd., 1936, 11,652. (Ref. in Zentralorg.f.ges. Chir., $1937,82,603)$.

8) De Blasio, Rinasc. med., 1937, 14,691.

9) Aleksandrowic z, Lek. wojsk., 1937, 28, 399. (Ref. in Zentralorg. f. ges. Chir., 1937, 85, 353).

10) Dom a nig, Wien. klin. Wschr., 1937, 1067.

11) Bagdassarov, Sang, 1937, 11, 466.

12) Wils on u. Jamies o n, Brit. Med. Journ., 1938, 1207.

13) R zepecki, Polski Przegl. Chir., 1938, 17, 437. (Ref. in Zentralorg. f. ges. Chir., 1938, 89, 670).

14) Heim, Dtsch. med. Wschr, 1939, 586. 
Menschen und Tier den Nachweis erbracht, dass man von der Transfusion des in vitro auf einen bestimmten Zeitraum aufbewahrten Blutes fast gleichen Erfolg wie bei der Transfusion frischen Blutes erwarten kann. Auch von Judin u. Skundina, ${ }^{15)} \mathrm{Yudin}{ }^{16)}$ ist beim Hund und Menschen die Beobachtung gemacht worden, dass die Transfusion des 6-8 Std.post mortem entnommenen Blutes keinen grossen Untersehied von derselben des frischen Blutes aufweist und ferner dass dasselbe Blut im Eisschrank 3 Wochen lang ohne jegliche Veränderung aufbewahrt werden kann. In jüngster Zeit hat Kigu c hi ${ }^{17)}$ am Menschen und Kaninchen diesbezügliche eingehende Untersuchungen angestellt und konnte bestätigen, dass, während beim Menschen 600 Std. lang (25 Tage) aufbewahrtes Blut angewandt werden kann, beim Kaninchen aber 2112 Std. lang (88 Tage) konserviertes Blut noch ohne nennenswerte Nebenwirkung zur Transfusion benutzt werden kann.

Das Blut ist bekanntermassen aus zelligen und flüssigen Bestandteilen zusammengesetzt; von vornherein ist es also zu erwarten, dass wenn das Blut in vitro aufbewahrt wird, zellige Bestand teile des Blutes zur Erfüllung ihrer Lebensbedingungen auf flüssige Beštandteile irgendwelche Einflüsse ausüben werden, während auch die ersteren anderseits durch Zustandsänderung der letzteren, also der umgebenden Flïssigkeit beeinflusst werden, so dass beide sich unter inniger Wechselbeziehung verändern können. Die Fragestellung mithin, ob und inwieweit das Blut durch Aufbewahrtwerden in vitro in morphologischer, serologischer und chemischer Hinsicht beeinflusst wiirde, muss heũte, wo die Transfusion konservierten Blutes praktische Anwendung findent, als Fundamentalbedingung nun erst recht erforscht werden. Überraschenderweise liegen diesbezügliche Untersuchungen bisher sehr wenig vor.

Über die Veränderungen der Form, Zahl, des Widerstandes und der Senkungsgeschwindigkeit der Erythrozyten sowie uiber die Phagozytose der Leukozyten, also über Veränderungen, welche sich auf zellige Bestandteile beziehen, liegen die Angaben von Bogdanov, ${ }^{18)}$ Doepp, ${ }^{19)}$ Karavanov, ${ }^{20)}$

15) Judin u. Skandina, Wien. med. Wsehr., 1934, 817.

16) Y pdin, Journ. Amer. Med. Assoc, 1936, 106, 997.

17) Kiguchi, Mitteil. aus der Med. Akad. zu Kioto, 1935, 13, 1097.

18) . B ogdanov, Verh. d. i. Konf. f. Bluttransfusion, Leningrad, 1933, 12, 19 (Russisch). (Ref. in Zentralorg. f. ges. Chir., 1934, 68, 330).

19) Doepp, Deutsch. Ztschr. f. Chir., 1934, 243, 736.

20) Ka ra va n ov, Nov. chir. Arch., 1934, 32, 87. (Ref. in Zentralorg. f. ges. Chir., $1936,77,513)$. 
Oganesjan, Salkind, u. Kudrjavceva, ${ }^{21)} \mathrm{Blochin}{ }^{22)} \mathrm{Kiguch}^{12)}$ vor. Über das Glutathion, $\mathrm{pH}$ und die Immunkörper des Blutes ist die Untersuchung von $\mathrm{Kiguchi}{ }^{17)}$ allein durchgeführt worden, und sehr spärlich ist auch die Zahl der Untersuchungen, die sich mit Veründerungen der chemischen, im Blut enthaltenen Substanzen befassen. Iv a chin en $\mathrm{k}^{23)}$ hat wahrgenommen, dass wenn das Menschenblut im Eisschrank aufbewahrt ist, der Blutzucker durch Glykolyse aus sich die Milchsäure entstehen lässt, so dass Reservealkali abnimmt. Kremerman ${ }^{24}$ sah im Menschenblut, das 12 Tage lang in Eisschrank aufbewahrt war, eine Zunahme des Rest-N. Des weiteren machte Balo ${ }^{25}$ die Beobachtung, dass im Blut (bei Kaninchen, Gänse, Hund und Menschen), welches bei $37^{\circ} \mathrm{C}$ luftdicht $72 \mathrm{Std}$. lang aufbewahrt war, Abnahme des Blutzuckers und Steigerung der H-Ionenkonzentration, also die azidotische Neigung auftrat, und die Ursache hierfür sieht er ausser in der Vermehrung der Milchsäure auch in der Bildung der anorganischen Phosphorsäure.

Das Blut kann eigentlich als ein zirkulierendes Gewebe betrachtet werden, es entsprechen nämlich seine zelligen Elemente den Gewebszellen und das Plasma ist mit der Gewebsflüssigkeit zu vergleichen. Wenn das Blut in vitro aufbewahrt ist, so vollzieht sich die Atmung der Blutzellen auf eine bestimmte Zeitspanne, weil diese den Saurerstoff reichlich in sich beibehalten, wobei mancherlei, mit ihren Lebensvorgängen einhergehende Erscheinungen angetroffen werden. Die Bestrebung, derartige Erscheinungen auf verschiedene Richtungen hin zu analysieren, kann deshalb nicht allein zur Frage der Transfusion konservierten Blutes beitragen, sondern sie ist auch für die Erforschung und Erfassung der Lebenserscheinung der Blutzellen, insbesondere aber der pathologischen Physiologie desselben ausserordentlich wichtig.

In volliegenden Versuchen habe ich mich mit dem Studium über die unter der Zelltätigkeit bekanntesten Vorgänge, also die Zellatmung, die Glykolyse, welche angeblich durch das glykolytische Ferment in Blutzellen bewirkt wird, and über die Permeabilität der Blutzellen sowie iber quantitative und qualitative Verhältnisse der mit der Zellfunktion aufs innigste zusammenhängenden Eiweisskörper be-

21) Oganesjan, Salkind u. Kudrjaveeva, Vestr. Chir, 1935, 38, 132 (Russisch). (Ref. in Zentralorg. f. ges. Chir., 1936, 76, 174). $89,369)$

22) Blochin, Chirurgija, 1937, 19,51. (Ref. in Zentralorg. f.gesamt. Chir., 1938,

23) Ivachnenko, Trudy rostov. med. Inst., 1985, 2, 52. (Ref. in Zentralorg. f. ges. Chir., 1937, 89, 115).

24) Kremerman, Eksper. med, 1938, 25, (Ref. in Kongresszentralbl. f. ges. inn. Med, 1938, 97, 521).

25) Bal ó, Pflüger's Arch., 1938, 239, 726. 
schäftigt, indem als Versuchsmaterial die den unter normalen und pathologischen Bedingungen befindlichen Kaninchen entnommenen, steril in vitro aufbewahrten Blutproben benutzt wurden.

Die Aufbewahrungsfrist des Blutes wurde auf 10 Tage erstreckt; es wurden die Atmungsfähigkeit aus dem $\mathrm{O}_{2}$-Verbrauch, die Glykolyse aus $\mathrm{Ab}$ - und Zunahme des Blutzuckers sowie der Milchsäure berechnet, und ferner das Eiweiss wurde durch Ermittelung seiner Konzentrationsänderung und des Ab- und Anstiegs des kolloidosmotischen Drucks auf seine quantitativen und qualitativen Veränderungen geprüft.

Versuchsmethode. Als Versuchsobjekt kam das Kaninchenblut zur Anwendung. Zunächst wurde im nüchternen Zustand das Blut unter streng aseptischen Kautelen aus der A. carotis entnommen und durch energisches Umschütteln defibriniert und dann mit dem Sauerstoff gesättigt. Dieses Blut wurde in 2 Proben geteilt, je $2 \mathrm{ccm}$ von der einen Blutprobe wurden in 6 kleine Glaszylinder, deren jeder von etwa 3,5 ccm Inhalt und mit einem Stöpsel und mit 2 Glasperlchen versehen war, gegeben, worauf jeder Glaszylinder mit sterilisiertem flüssigen Paraffin uberschichtet und mit dem. Stöpsel luftdicht verschlossen wurde. Von der anderen Blutprobe wurden ebenfalls je $2 \mathrm{ccm}$ in 6 kleine Reagenzröhrchen mit 2 Glasperlchen getan, jedes Reagenzröhrchen wurde ebenfalls mit flüssigem Paraffin überschichtet und luftdicht verschlossen.

Diese 2 Blutproben wurden unter den gleichen Bedingungen im Eisschrank bei $0-5^{\circ} \mathrm{C}$ aufbewahrt. Diese Linteilung der Blutproben in 2 Gruppen erfolgte aus dem Grund, weil man mit dem in den Glaszylindern aufbewahrten Blut, also Vollblut die $\mathrm{O}_{2}$-Kapazität, den Blutzucker und die Blutmilchsäure zu bestimmen und mit dem in den Reagenzröhrchen aufbewahrten Blut, nach Absonderung des Serums, daran die Bestimmungen von Eiweissgehalt, kolloid-osmotischen Druck und $\mathrm{NaCl}$ vorzunehmen beabsichtigte.

Um zunächst Vorwerte festzustellen, wurde an in einem Glaszylinder befindlichem Blut die $\mathrm{O}_{2}$-Kapazität mit dem Barcroft's Differential-Blutgasapparat ${ }^{26)}$ bestimmt, während an übrigen Blutportionen dieser Gruppe den Blutzucker nach der Methode von Hagedorn u. Jensens, die Blutmilchsäure mit der von Inawashiro u. Hayasaka ${ }^{27)}$ modifizierten Methode von Anrep u. Cannan bestimmte, und mit dem in einem anderen Reagenzröhrchen aufbewahrten

26) Barcroft, The respiratory function of the blood, Carnbridge, 1914.

27) In awashirou. Hayas a ka, Tohoku Journ. Exp. Med., 1928, 12, 1. 
Blut, wurden nach Absonderung des Serums das Serumeiweiss mittels des Pulfrich'schen Eintauchrefraktometers, der kolloid-osmotische Druck (im folgenden kurz als k.o.D. bezeichnet) und der kolloid-osmotische Druck für $1 \%$ Eiweiss (Druck pro \%) nach der Methode von Kroghu.Nakaza wa a ${ }^{28}$ und das $\mathrm{NaCl}$ nach der Rus z nyák's Methode gemessen.

An den ubrigen, sowohl in Glaszylindern wie auch in Reagenzröhrchen aufbewahrten Blutportionen wurden die Parallelbestimmungen der oben angeführten Grössen in den Zeitabständen von 48, 96, 144, 192 und $240 \mathrm{Std}$. vorgenommen. Im übrigen wurden die Blutproben in Glaszylindern und Reagenzröhrchen jeden Tag einmal umgeschüttelt, damit Sera und Erythrozyten durchgemischt werden konnten.

\section{Versuch am normalen Kaninchenbliut.}

Es wurden die Bestimmungen an Blutproben, welche 8 gesunden Kaninchen von 1,8-2,4 kg Körpergewicht entnommen und 10 Tage lang aufbewahrt wurden, ausgeführt. Die hierbei gewonnenen Resultate sind in Tab. 1 zusammengestellt, auch in beistehender Fig. 1 sind die Daten mit prozentischer Ab- und Zunahme den Durchschnittswerten nach illustriert.

$\mathrm{O}_{2}-$ Verbrauch: Die Atmung der Erythrozyten vollzieht sich, nach Zunahme der $\mathrm{O}_{2}$-Unsättigung beurteilt, in Anfangsstadien langsam und dann ziemlich rasch, indem sie in zehntägiger Aufbewahrungsdauer 14,7-27,6\%, im Mittel 20,9\% des anfangs sich vorfindenden $\mathrm{O}_{2}$-Gehaltes verbrauchten. Die nähere Verfolgung der $\mathrm{O}_{2}$-Kapazität ergab, dass sie mit dem Zeitverlauf allmählich um äusserst Geringes abnahm, um schliesslich eine prozentige Abnahme von 1,4-5,5\%, im Mittel 2,7\% aufzuweisen. Dies deutet zweifelsohne darauf hin, dass das Blut durch die Aufbewahrung am Vermögen, sich mit dem Sauerstoff zu binden, verliert.

Serumeiweiss und k.o.D.: Die Konzentration des Serumeiweisses und der k.o.D. zeigten, abgesehen von geringen Schwankungen in manchen Fällen, im grossen ganzen keine bedeutende $\mathrm{Ab}$ - und $\mathrm{Zu}$ nahme. Mithin änderte sich nichts an Druck pro \%. Es lässt sich also sagen, dass bei normalem Blut, welches 10 Tage lang steril aufbewahrt wurde, dessen Eiweiss weder quantitative noch qualitative Veränderung aufweist.

28) - Krogh u. Nakazawa, Biochem. Ztschr., 1927, 188, 241. 
Serü-NaCl: Fast keine Veränderung war anzutreffen.

Blutzucker und Blutmilchsäure: Im Gegensatz zu Serumeiweiss, k.o.D. und Serum-NaCl, welche alle fast keine Veränderungen aufwiesen, erfuhr der Blutzucker durch Glykolyse beträchtliche Veränderungen. Der Blutzuckergehalt nämlich verminderte sich mit dem Zeitablauf, wohingegen die Blutmilchsäure vermehrt war. 'Die Kurve des Blutzuckers fiel im grossen ganzen geradelinig ab, während die Blutmilchsäure in beinahe Gegenbild dazu in die Höhe ging. In 10tägigem Verlauf erfuhr der Blutzucker eine Abnahme von 48,4$70,4 \%$, im Mittel $61,5 \%$, wogegen die Milchsäure in gleicher Zeitspanne eine Zunahme von 27,7-59,0\%, im Mittel 45,4\% aufwies. Im allgemeinen fand die Zunahme der Milchsäure nicht gerade umgekehrt proportional der Abnahme des Zuckers statt, sondern die Zunahme der ersteren stand derselben des letzteren an Grad mehr oder weniger nach.

Aus obigen Ergebnissen geht hervor, dass im normalen Blut infolge der Aufbewahrung die vermehrte $\mathrm{O}_{2}$-Unsättigung des Blutes durch Exythrozytenatmung, die Abnahme des Blutzuckers durch Glykolyse und die damit einhergehende Zunahine der Blutmilchsäure sich einstellen, während das Serumeiweiss und der k. o. D. kaum beeinflusst werden. Die Feststellung, dass die $\mathrm{O}_{2}$-Kapazität mit dem Zeitablauf verringert ist, dürfte wahrscheinlich auf den mit vermehrter Milchsäurebildung im Blut einhergehenden $\mathrm{pH}$-Änderungen beruhen.

\section{Versuch am azidotischen Blut.}

Dass durch die pH-Änderung des Blutes die $\mathrm{O}_{2}$-Dissoziationskurve des Blutes sich verändert, ist schon aus früherer Zeit durch Untersuchungen von Bohr, Hasselbalchu. Krogh, ${ }^{29)} \mathrm{Barcroft} u$. Camis, ${ }^{30)}$ Mathison ${ }^{31)}$ Oinuma ${ }^{32)} \mathrm{Kato}^{33)}{ }^{33}$ Momose, ${ }^{34)}$ Yamakita ${ }^{35)}$ u.a. erkannt worden. Dieser Umstand deutet gerade darauf hin, dass die $\mathrm{pH}$ Änderung zwangsläufig einen wesentlichen Einfluss auf den Lebensvorgang der Erythrozyten ausübt. Wie bereits im vorherigen Kapitel besprochen wurde, kommt es auch bei normalem Blut bei langdauernder Aufbewahrung durch vermehrte Milchsäurebildung zu pH-Änderung.

29) Bohr, Hasselbaleh n. Krogh, Skandinav. Arch. f. Physiol., 1904, 16, 402.

30) B.arcroft u. Camis, Journ. Physiol., 1909-10, 30, 118.

31) Mathis on, Ibid., 1911-12, 43, 347.

32) Oinuma, Ibid., 1911-12, 43,364.

33) Ka to, Biochem. Journ., 1915, 9, 393.

34) Momose, Ibid., 1915, 9, 485.

35) Y a m a ki ta, Tohoku Journ. Exp. Med., 1921, 2, 290. 
Tabelle 1. Bestimmungen

\begin{tabular}{|c|c|c|c|c|c|c|}
\hline \multirow{2}{*}{$\begin{array}{c}\text { Blut- } \\
\text { Nr. }\end{array}$} & \multirow{2}{*}{$\begin{array}{l}\text { Zeit- } \\
\text { ablauf } \\
\text { Stad. }\end{array}$} & \multirow{2}{*}{$\begin{array}{l}\mathrm{O}_{\mathrm{z}}-\mathrm{Un}- \\
\text { sätigung } \\
\%\end{array}$} & \multicolumn{2}{|c|}{$\mathrm{O}_{2}$-Kapazität } & \multicolumn{2}{|c|}{ Serumeiweiss } \\
\hline & & & $\begin{array}{l}\text { ecm in } \\
109 \mathrm{ccm}\end{array}$ & $\begin{array}{c}\text { Diff, in } \\
\%\end{array}$ & $\%$ & $\begin{array}{c}\text { Diff. in } \\
\%\end{array}$ \\
\hline 1 & $\begin{array}{r}\text { vor } \\
48 \\
96 \\
144 \\
192 \\
240 \\
\end{array}$ & $\begin{array}{r}0,9 \\
2,3 \\
5,5 \\
11,4 \\
27,6 \\
\end{array}$ & $\begin{array}{l}18,27 \\
18,12 \\
17,98 \\
17,77 \\
17,56 \\
17,29 \\
\end{array}$ & $\begin{array}{l}-0,8 \\
-1,6 \\
-2,7 \\
-3,9 \\
-5,4 \\
\end{array}$ & $\begin{array}{l}6,55 \\
6,55 \\
6,55 \\
6,55 \\
6,56 \\
6,56 \\
\end{array}$ & $\begin{array}{l} \pm 0 \\
\pm 0 \\
\pm 0 \\
+0,1 \\
+0,1 \\
\end{array}$ \\
\hline 2 & $\begin{array}{r}\text { vor } \\
48 \\
96 \\
144 \\
192 \\
240 \\
\end{array}$ & $\begin{array}{r}1,6 \\
4,3 \\
8,4 \\
14,6 \\
26,0 \\
\end{array}$ & $\begin{array}{l}15,50 \\
15,40 \\
15,25 \\
15,12 \\
14,87 \\
14,64 \\
\end{array}$ & $\begin{array}{l}-0,6 \\
-1,6 \\
-2,4 \\
-4,1 \\
-5,5\end{array}$ & $\begin{array}{l}5,97 \\
5,97 \\
5,97 \\
5,97 \\
5,97 \\
5,97 \\
\end{array}$ & $\begin{array}{l} \pm 0 \\
\pm 0 \\
\pm 0 \\
\pm 0 \\
\pm 0\end{array}$ \\
\hline 3 & $\begin{array}{r}\text { vor } \\
48 \\
96 \\
144 \\
192 \\
240 \\
\end{array}$ & $\begin{array}{r}1,3 \\
3,1 \\
6,7 \\
13,0 \\
19,4 \\
\end{array}$ & $\begin{array}{l}18,73 \\
18,68 \\
18,65 \\
18,53 \\
18,44 \\
18,35 \\
\end{array}$ & $\begin{array}{r}-0,3 \\
-0,4 \\
-1,1 \\
-1,5 \\
-2,0 \\
\end{array}$ & $\begin{array}{l}6,34 \\
6,34 \\
6,34 \\
6,35 \\
6,34 \\
6,34 \\
\end{array}$ & $\begin{array}{l} \pm 0 \\
\pm 0 \\
+0,1 \\
\pm 0 \\
\pm 0 \\
\end{array}$ \\
\hline 4 & $\begin{array}{r}\text { vor } \\
48 \\
96 \\
144 \\
192 \\
.240 \\
\end{array}$ & $\begin{array}{r}1,7 \\
4,0 \\
6,5 \\
14,4 \\
24,4 \\
\end{array}$ & $\begin{array}{l}19,29 \\
19,19 \\
19,11 \\
18,98 \\
18,86 \\
18,76\end{array}$ & $\begin{array}{l}-0,5 \\
-0,9 \\
-1,6 \\
-2,2 \\
-2,7 \\
\end{array}$ & $\begin{array}{l}5,68 \\
5,68 \\
5,68 \\
5,68 \\
5,68 \\
5,68 \\
\end{array}$ & $\begin{array}{l} \pm 0 \\
\pm 0 \\
\pm 0 \\
\pm 0 \\
\pm 0\end{array}$ \\
\hline 5 & $\begin{array}{r}\text { vor } \\
48 \\
96 \\
144 \\
192 \\
240 \\
\end{array}$ & $\begin{array}{r}1,3 \\
3,5 \\
8,0 \\
11,6 \\
20,2 \\
\end{array}$ & $\begin{array}{l}18,43 \\
18,38 \\
18,30 \\
18,26 \\
18,18 \\
18,09 \\
\end{array}$ & $\begin{array}{l}-0,3 \\
-0,7 \\
-0,9 \\
-1,3 \\
-1,8 \\
\end{array}$ & $\begin{array}{l}5,79 \\
5,79 \\
5,79 \\
5,79 \\
5,79 \\
5,79 \\
\end{array}$ & $\begin{array}{l} \pm 0 \\
\pm 0 \\
\pm 0 \\
\pm 0 \\
\pm 0\end{array}$ \\
\hline 6 & $\begin{array}{r}\text { vor } \\
48 \\
96 \\
144 \\
192 \\
240 \\
\end{array}$ & $\begin{array}{r}1,4 \\
2,3 \\
4,6 \\
10,0 \\
14,7 \\
\end{array}$ & $\begin{array}{l}17,90 \\
17,88 \\
17,82 \\
17,71 \\
17,69 \\
17,65 \\
\end{array}$ & $\begin{array}{l}-0,1 \\
-0,4 \\
-1,1 \\
-1,2 \\
-1,4\end{array}$ & $\begin{array}{l}5,94 \\
5,94 \\
5,94 \\
5,94 \\
5,94 \\
5,94 \\
\end{array}$ & $\begin{array}{l} \pm 0 \\
\pm 0 \\
\pm 0 \\
\pm 0 \\
\pm 0\end{array}$ \\
\hline 7 & $\begin{array}{r}\text { vor } \\
48 \\
96 \\
144 \\
192 \\
240 \\
\end{array}$ & $\begin{array}{r}1,0 \\
1,9 \\
3,9 \\
7,8 \\
16,5\end{array}$ & $\begin{array}{l}17,41 \\
17,37 \\
17,32 \\
17,29 \\
17,18 \\
17,14\end{array}$ & $\begin{array}{l}-0,2 \\
-0,5 \\
-0,7 \\
-1,3 \\
-1,5 \\
\end{array}$ & $\begin{array}{l}5,77 \\
5,77 \\
5,77 \\
5,77 \\
5,77 \\
5,77 \\
\end{array}$ & $\begin{array}{l} \pm 0 \\
\pm 0 \\
\pm 0 \\
\pm 0 \\
\pm 0\end{array}$ \\
\hline 8 & $\begin{array}{r}\text { vor } \\
48 \\
96 \\
144 \\
192 \\
240 \\
\end{array}$ & $\begin{array}{r}2,0 \\
3,0 \\
5,4 \\
12,1 \\
18,5 \\
\end{array}$ & $\begin{array}{l}16,91 \\
16,82 \\
16,74 \\
16,71 \\
16,66 \\
16,63 \\
\end{array}$ & $\begin{array}{l}-0,5 \\
-1,0 \\
-1,2 \\
-1,5 \\
-1,6\end{array}$ & $\begin{array}{l}6,10 \\
6,10 \\
6,12 \\
6,10 \\
6,10 \\
6,10 \\
\end{array}$ & $\begin{array}{l} \pm 0 \\
\pm 0,3 \\
\pm 0 \\
\pm 0 \\
\pm 0\end{array}$ \\
\hline $\begin{array}{l}\text { Durch- } \\
\text { schnitt }\end{array}$ & $\begin{array}{r}\text { vor } \\
48 \\
96 \\
144 \\
192 \\
240\end{array}$ & $\begin{array}{r}1,4 \\
3,0 \\
6,1 \\
11,9 \\
20,9\end{array}$ & $\begin{array}{l}17,80 \\
17,73 \\
17,65 \\
17,55 \\
17,43 \\
17,31\end{array}$ & $\begin{array}{l}-0,4 \\
-0,9 \\
-1,5 \\
-2,1 \\
-2,7\end{array}$ & $\begin{array}{l}6,02 \\
6,02 \\
6,02 \\
6,02 \\
6,02 \\
6,02\end{array}$ & $\begin{array}{l} \pm 0 \\
\pm 0 \\
\pm 0 \\
\pm 0 \\
\pm 0\end{array}$ \\
\hline
\end{tabular}


am normalen Kaninchenblut.

\begin{tabular}{|c|c|c|c|c|c|c|c|c|c|}
\hline \multicolumn{2}{|c|}{ K:o.D. } & \multicolumn{2}{|c|}{ Druck pro \% } & \multicolumn{2}{|c|}{ Serum-NaCl } & \multicolumn{2}{|c|}{ Blutzucker } & \multicolumn{2}{|c|}{ Blutmilchsäure } \\
\hline $\begin{array}{l}\mathrm{mm} \\
\mathrm{H}_{2} \mathrm{O}\end{array}$ & $\underset{\%}{\text { Diff in }}$ & $\underset{\mathrm{H}_{2} \mathrm{O}}{\mathrm{mm}}$ & $\begin{array}{c}\text { Diff, in } \\
\text { \% }\end{array}$ & $\mathrm{mg} / \mathrm{dl}$ & $\begin{array}{l}\text { Diff. in } \\
\%\end{array}$ & $\mathrm{mg} / \mathrm{dl}$ & $\underset{: 0}{\text { Diff, in }}$ & $\mathrm{mg} / \mathrm{dl}$ & $\begin{array}{c}\text { Diff, in } \\
\% \text {. }\end{array}$ \\
\hline $\begin{array}{l}280 \\
280 \\
280 \\
280 \\
280 \\
280 \\
\end{array}$ & $\begin{array}{l} \pm 0 \\
\pm 0 \\
\pm 0 \\
\pm 0 \\
\pm 0\end{array}$ & $\begin{array}{l}42,7 \\
42,7 \\
42,7 \\
42,7 \\
42,7 \\
42,7 \\
\end{array}$ & $\begin{array}{l} \pm 0 \\
\pm 0 \\
\pm 0 \\
\pm 0 \\
\pm 0\end{array}$ & $\begin{array}{l}570 \\
570 \\
570 \\
570 \\
575 \\
575 \\
\end{array}$ & $\begin{array}{l} \pm 0 \\
\pm 0 \\
\pm 0 \\
+0,9 \\
+0,9\end{array}$ & $\begin{array}{l}81 \\
75 \\
66 \\
41 \\
32 \\
24 \\
\end{array}$ & $\begin{array}{l}-7,4 \\
-18,5 \\
-49,4 \\
-60,5 \\
-70,4 \\
\end{array}$ & $\begin{array}{l}25,07 \\
27,64 \\
30,86 \\
32,79 \\
36,64 \\
39,86 \\
\end{array}$ & $\begin{array}{r}+10,2 \\
+23,1 \\
+30,8 \\
+46,1 \\
+59,0 \\
\end{array}$ \\
\hline $\begin{array}{l}260 \\
260 \\
260 \\
260 \\
260 \\
259\end{array}$ & $\begin{array}{l} \pm 0 \\
\pm 0 \\
\pm 0 \\
\pm 0 \\
-0,4\end{array}$ & $\begin{array}{l}43,5 \\
43,5 \\
43,5 \\
43,5 \\
43,5 \\
43,4 \\
\end{array}$ & $\begin{array}{l} \pm 0 \\
\pm 0 \\
\pm 0 \\
\pm 0 \\
-0,2\end{array}$ & $\begin{array}{l}550 \\
550 \\
550 \\
550 \\
550 \\
550 \\
\end{array}$ & $\begin{array}{l} \pm 0 \\
\pm 0 \\
\pm 0 \\
\pm 0 \\
\pm 0\end{array}$ & $\begin{array}{l}90 \\
84 \\
75 \\
59 \\
48 \\
34 \\
\end{array}$ & $\begin{array}{l}-6,7 \\
-16,7 \\
-34,4 \\
-46,7 \\
-62,2\end{array}$ & $\begin{array}{l}32,79 \\
36,00 \\
40,50 \\
44,36 \\
46,93 \\
50,76 \\
\end{array}$ & $\begin{array}{r}+9,8 \\
+23,5 \\
+85,3 \\
+43,1 \\
+54,8 \\
\end{array}$ \\
\hline $\begin{array}{l}277 \\
277 \\
277 \\
278 \\
277 \\
277\end{array}$ & $\begin{array}{l} \pm 0 \\
\pm 0 \\
+0,4 \\
\pm 0 \\
\pm 0\end{array}$ & $\begin{array}{l}43,7 \\
43,7 \\
43,7 \\
43,8 \\
43,7 \\
43,7 \\
\end{array}$ & $\begin{array}{l} \pm 0 \\
\pm 0 \\
+0,2 \\
\pm 0 \\
\pm 0\end{array}$ & $\begin{array}{l}630 \\
630 \\
630 \\
630 \\
630 \\
630 \\
\end{array}$ & $\begin{array}{ll} \pm & 0 \\
\pm & 0 \\
\pm & 0 \\
\pm & 0 \\
\pm & 0\end{array}$ & $\begin{array}{r}115 \\
104 \\
95 \\
79 \\
66 \\
45 \\
\end{array}$ & $\begin{array}{r}9,6 \\
-17,4 \\
-31,3 \\
-42,6 \\
-60,9 \\
\end{array}$ & $\begin{array}{l}37,29 \\
39,86 \\
43,07 \\
47,57 \\
52,07 \\
57,21 \\
\end{array}$ & $\begin{array}{r}+6,9 \\
+15,5 \\
+27,6 \\
+39,6 \\
+53,4 \\
\end{array}$ \\
\hline $\begin{array}{l}248 \\
248 \\
248 \\
248 \\
248 \\
248 \\
\end{array}$ & $\begin{array}{l} \pm 0 \\
\pm 0 \\
\pm 0 \\
\pm 0 \\
\pm 0\end{array}$ & $\begin{array}{l}43,7 \\
43,7 \\
43,7 \\
43,7 \\
43,7 \\
43,7\end{array}$ & $\begin{array}{ll} \pm & 0 \\
\pm & 0 \\
\pm & 0 \\
\pm & 0 \\
\pm & 0\end{array}$ & $\begin{array}{l}520 \\
520 \\
520 \\
520 \\
520 \\
520 \\
\end{array}$ & $\begin{array}{l} \pm 0 \\
\pm 0 \\
\pm 0 \\
\pm 0 \\
\pm 0\end{array}$ & $\begin{array}{r}111 \\
99 \\
79 \\
65 \\
48 \\
34 \\
\end{array}$ & $\begin{array}{r}-10,8 \\
-28,8 \\
-41,4 \\
-56,7 \\
-69,4 \\
\end{array}$ & $\begin{array}{l}28,29 \\
30,86 \\
33,43 \\
36,00 \\
37,93 \\
41,14 \\
\end{array}$ & $\begin{array}{r}+9,1 \\
+18,2 \\
+27,2 \\
+34,1 \\
+45,4 \\
\end{array}$ \\
\hline $\begin{array}{l}228 \\
228 \\
229 \\
228 \\
228 \\
228 \\
\end{array}$ & $\begin{array}{l} \pm 0 \\
+0,4 \\
\pm 0 \\
\pm 0 \\
\pm 0\end{array}$ & $\begin{array}{l}39,4 \\
39,4 \\
39,5 \\
39,4 \\
39,4 \\
39,4 \\
\end{array}$ & $\begin{array}{l} \pm 0 \\
+0,2 \\
\pm 0 \\
\pm 0 \\
\pm 0\end{array}$ & $\begin{array}{l}555 \\
555 \\
555 \\
550 \\
555 \\
555 \\
\end{array}$ & $\begin{array}{l} \pm 0 \\
\pm 0 \\
\pm 0,9 \\
\pm 0 \\
\pm 0\end{array}$ & $\begin{array}{r}120 \\
104 \\
88 \\
68 \\
57 \\
43\end{array}$ & $\begin{array}{r}-18,3 \\
-26,7 \\
-43,3 \\
-52,5 \\
-64,2\end{array}$ & $\begin{array}{l}32,14 \\
34,07 \\
36,64 \\
40,50 \\
43,71 \\
45,64 \\
\end{array}$ & $\begin{array}{r}+6,0 \\
+14,0 \\
+26,0 \\
+36,0 \\
+42,0 \\
\end{array}$ \\
\hline $\begin{array}{l}200 \\
200 \\
200 \\
200 \\
200 \\
200\end{array}$ & $\begin{array}{l} \pm 0 \\
\pm 0 \\
\pm 0 \\
\pm 0 \\
\pm 0\end{array}$ & $\begin{array}{l}33,7 \\
33,7 \\
33,7 \\
33,7 \\
33,7 \\
33,7 \\
\end{array}$ & $\begin{array}{l} \pm 0 \\
\pm 0 \\
\pm 0 \\
\pm 0 \\
\pm 0\end{array}$ & $\begin{array}{l}545 \\
540 \\
545 \\
545 \\
545 \\
545 \\
\end{array}$ & $\begin{array}{l}-0,9 \\
\pm 0 \\
\pm 0 \\
\pm 0 \\
\pm 0\end{array}$ & $\begin{array}{r}113 \\
106 \\
99 \\
81 \\
65 \\
52 \\
\end{array}$ & $\begin{array}{l}-6,2 \\
-12,4 \\
-28,3 \\
-42,5 \\
-54,0\end{array}$ & $\begin{array}{l}26,36 \\
28,29 \\
30,21 \\
32,79 \\
34,71 \\
36,64 \\
\end{array}$ & $\begin{array}{r}+7,3 \\
+14,6 \\
+24,4 \\
+31,7 \\
+39,0 \\
\end{array}$ \\
\hline $\begin{array}{l}216 \\
216 \\
216 \\
216 \\
216 \\
216\end{array}$ & $\begin{array}{l} \pm 0 \\
\pm 0 \\
\pm 0 \\
\pm 0 \\
\pm 0\end{array}$ & $\begin{array}{l}37,4 \\
37,4 \\
37,4 \\
37,4 \\
37,4 \\
37,4\end{array}$ & $\begin{array}{l} \pm 0 \\
\pm 0 \\
\pm 0 \\
\pm 0 \\
\pm 0\end{array}$ & $\begin{array}{l}550 \\
550 \\
545 \\
550 \\
550 \\
550\end{array}$ & $\begin{array}{l} \pm 0 \\
-0,9 \\
\pm 0 \\
\pm 0 \\
\pm 0\end{array}$ & $\begin{array}{l}97 \\
90 \\
77 \\
65 \\
54 \\
36 \\
\end{array}$ & $\begin{array}{r}7,2 \\
-20,6 \\
-33,0 \\
-44,3 \\
-62,9 \\
\end{array}$ & $\begin{array}{l}31,50 \\
33,43 \\
35,36 \\
37,93 \\
41,14 \\
44,36\end{array}$ & $\begin{array}{r}+6,1 \\
+12,2 \\
+20,4 \\
+30,6 \\
+40,8 \\
\end{array}$ \\
\hline $\begin{array}{l}259 \\
259 \\
259 \\
260 \\
259 \\
259\end{array}$ & $\begin{array}{l} \pm 0 \\
\pm 0 \\
+0,4 \\
\pm 0 \\
\pm 0\end{array}$ & $\begin{array}{l}42,4 \\
42,4 \\
42,3 \\
42,6 \\
42,4 \\
42,4\end{array}$ & $\begin{array}{l} \pm 0 \\
-0,2 \\
+0,5 \\
\pm 0 \\
\pm 0\end{array}$ & $\begin{array}{l}540 \\
540 \\
540 \\
535 \\
540 \\
540\end{array}$ & $\begin{array}{l} \pm 0 \\
\pm 0 \\
=0,9 \\
\pm 0 \\
\pm 0\end{array}$ & $\begin{array}{l}93 \\
84 \\
72 \\
63 \\
54 \\
48 \\
\end{array}$ & $\begin{array}{r}9,7 \\
-22,6 \\
-32,2 \\
-41,9 \\
-48,4 \\
\end{array}$ & $\begin{array}{l}30,21 \\
32,14 \\
34,07 \\
35,36 \\
37,29 \\
38,57\end{array}$ & $\begin{array}{r}+6,4 \\
+12,8 \\
+17,0 \\
+23,4 \\
+27,7 \\
\end{array}$ \\
\hline $\begin{array}{l}246 \\
246 \\
246 \\
246 \\
246 \\
246\end{array}$ & $\begin{array}{l} \pm 0 \\
\pm 0 \\
\pm 0 \\
\pm 0 \\
\pm 0\end{array}$ & $\begin{array}{l}40,8 \\
40,8 \\
40,8 \\
40,8 \\
40,8 \\
40,8\end{array}$ & $\begin{array}{l} \pm 0 \\
\pm 0 \\
\pm 0 \\
\pm 0 \\
\pm 0\end{array}$ & $\begin{array}{l}557 \\
557 \\
557 \\
556 \\
558 \\
558\end{array}$ & $\begin{array}{l} \pm 0 \\
\pm 0 \\
-0,2 \\
+0,2 \\
+0,2\end{array}$ & $\begin{array}{r}102 \\
93 \\
81 \\
65 \\
53 \\
39\end{array}$ & $\begin{array}{r}-8,9 \\
-20,5 \\
-36,7 \\
-48,5 \\
-61,5\end{array}$ & $\begin{array}{l}30,46 \\
32,79 \\
35,52 \\
38,41 \\
41,30 \\
44,27\end{array}$ & $\begin{array}{r}+7,7 \\
+16,7 \\
+26,1 \\
+35,6 \\
+45,4\end{array}$ \\
\hline
\end{tabular}


Tabelle

Bestimmungen am

\begin{tabular}{|c|c|c|c|c|c|c|c|c|c|c|}
\hline \multirow{2}{*}{$\begin{array}{c}\text { Blut- } \\
\mathrm{Nr} \text {. }\end{array}$} & \multirow{2}{*}{$\begin{array}{l}\text { Zeit- } \\
\text { ablauf } \\
\text { Std. }\end{array}$} & \multirow{2}{*}{$\begin{array}{c}\mathrm{O}_{2} \text {-Un- } \\
\text { sättig- } \\
\text { ung } \\
\%\end{array}$} & \multicolumn{2}{|c|}{$\mathrm{O}_{2}$ - Kapazität } & \multicolumn{2}{|c|}{ Serumeiweiss } & \multicolumn{2}{|c|}{ K.o.D. } & \multicolumn{2}{|c|}{ Druck pro $\%$} \\
\hline & & & $\mid \begin{array}{c}\text { cem in } \\
100 \\
\text { cem }\end{array}$ & $\underset{\%}{\text { Diff. in }}$ & $\%$ & $\underset{\%}{\text { Diff. in }}$ & 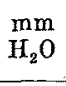 & $\begin{array}{c}\text { Diff. in } \\
\%\end{array}$ & $\underset{\mathrm{H}_{2} \mathrm{O}}{\mathrm{mm}}$ & $\underset{\%}{\text { Diff, in }}$ \\
\hline 1 & $\begin{array}{r}\text { vor } \\
48 \\
96 \\
144 \\
192 \\
240\end{array}$ & $\begin{array}{r}2,1 \\
5,9 \\
7,7 \\
9,1 \\
10,6\end{array}$ & $\begin{array}{l}16,57 \\
16,36 \\
16,25 \\
15,88 \\
15,54 \\
15,44\end{array}$ & $\begin{array}{r}-1,3 \\
-1,9 \\
-4,2 \\
-6,2 \\
-6,8\end{array}$ & $\begin{array}{l}5,70 \\
5,64 \\
5,68 \\
5,70 \\
5,70 \\
5,70\end{array}$ & $\begin{aligned} & 1,0 \\
- & 0,3 \\
\pm & 0 \\
\pm & 0 \\
\pm & 0\end{aligned}$ & $\begin{array}{l}249 \\
227 \\
230 \\
240 \\
240 \\
242\end{array}$ & $\begin{array}{r}-8,8 \\
-7,6 \\
-3,6 \\
-3,6 \\
-2,8\end{array}$ & $\begin{array}{r}43,7 \\
40,2 \\
40,5 \\
42,1 \\
\cdot 42,1 \\
42,4\end{array}$ & $\begin{array}{l}-8,0 \\
-7,3 \\
-3,7 \\
-3,7 \\
-3,0\end{array}$ \\
\hline 2 & $\begin{array}{r}\text { vor } \\
48 \\
96 \\
144 \\
192 \\
240\end{array}$ & $\begin{array}{l}1,2 \\
4,3 \\
5,6 \\
7,6 \\
8,9\end{array}$ & $\begin{array}{l}16,48 \\
16,27 \\
15,98 \\
15,71 \\
15,46 \\
15,21\end{array}$ & $\begin{array}{l}-1,3 \\
-3,0 \\
-4,7 \\
-6,2 \\
-7,7\end{array}$ & $\begin{array}{l}5,53 \\
5,40 \\
5,49 \\
5,49 \\
5,49 \\
5,51\end{array}$ & $\begin{array}{l}-2,3 \\
-0,7 \\
-0,7 \\
-0,7 \\
-0,4\end{array}$ & $\begin{array}{l}219 \\
203 \\
210 \\
213 \\
213 \\
215\end{array}$ & $\begin{array}{l}-7,3 \\
-4,1 \\
-2,7 \\
-2,7 \\
-1,8\end{array}$ & $\begin{array}{l}39,6 \\
37,6 \\
38,2 \\
38,8 \\
38,8 \\
39,0\end{array}$ & $\begin{array}{r}-5,0 \\
-3,5 \\
-2,0 \\
-2,0 \\
-1,5\end{array}$ \\
\hline 3 & $\begin{array}{r}\text { vor } \\
48 \\
96 \\
144 \\
192 \\
240\end{array}$ & $\begin{array}{l}1,6 \\
2,6 \\
3,1 \\
4,6 \\
5,4\end{array}$ & $\begin{array}{l}16,17 \\
15,98 \\
15,71 \\
15,54 \\
15,49 \\
15,45\end{array}$ & $\begin{array}{r}-1,2 \\
-2,8 \\
-3,9 \\
-4,2 \\
-4,4\end{array}$ & $\begin{array}{l}6,08 \\
6,03 \\
6,03 \\
6,05 \\
6,05 \\
6,05\end{array}$ & $\begin{array}{r}-0,8 \\
-0,8 \\
-0,5 \\
-0,5 \\
-0,5\end{array}$ & $\begin{array}{l}235 \\
220 \\
218 \\
223 \\
223 \\
224\end{array}$ & $\begin{array}{l}-6,4 \\
-7,2 \\
-5,1 \\
-5,1 \\
-4,7\end{array}$ & $\begin{array}{l}38,6 \\
36,5 \\
36,1 \\
36,8 \\
36,8 \\
37,0\end{array}$ & $\begin{array}{l}-5,4 \\
-6,5 \\
-4,7 \\
-4,7 \\
-4,1\end{array}$ \\
\hline 4 & $\begin{array}{r}\text { vor } \\
48 \\
96 \\
144 \\
192 \\
240\end{array}$ & $\begin{array}{l}2,2 \\
3,4 \\
6,4 \\
7,3 \\
9,3\end{array}$ & $\begin{array}{l}12,59 \\
12,41 \\
12,23 \\
12,20 \\
12,14 \\
12,06\end{array}$ & $\begin{array}{r}-1,4 \\
-2,8 \\
-3,1 \\
-3,6 \\
-4,2\end{array}$ & $\begin{array}{l}5,90 \\
5,81 \\
5,79 \\
5,83 \\
5,83 \\
5,86\end{array}$ & $\begin{array}{l}-1,5 \\
-1,9 \\
-1,2 \\
-1,2 \\
-0,7\end{array}$ & $\begin{array}{l}232 \\
217 \\
215 \\
220 \\
220 \\
223\end{array}$ & $\begin{array}{r}-6,5 \\
-7,3 \\
-5,2 \\
-5,2 \\
-3,9\end{array}$ & $\begin{array}{l}39,3 \\
37,3 \\
37,1 \\
37,7 \\
37,7 \\
38,0\end{array}$ & $\begin{array}{l}-5,1 \\
-5,6 \\
-4,1 \\
-4,1 \\
-3,3\end{array}$ \\
\hline 5 & $\begin{array}{r}\text { vor } \\
48 \\
96 \\
144 \\
192 \\
240\end{array}$ & $\begin{array}{l}0,5 \\
2,1 \\
4,4 \\
6,3 \\
7,8\end{array}$ & $\begin{array}{l}16,30 \\
16,12 \\
16,03 \\
15,91 \\
15,82 \\
15,72\end{array}$ & $\begin{array}{r}-1,1 \\
-1,6 \\
-2,4 \\
-2,9 \\
-3,5\end{array}$ & $\begin{array}{l}6,12 \\
6,03 \\
6,05 \\
6,08 \\
6,08 \\
6,08\end{array}$ & $\begin{array}{r}-1,5 \\
-1,1 \\
-0,6 \\
-0,6 \\
-0,6\end{array}$ & $\begin{array}{l}235 \\
219 \\
223 \\
230 \\
230 \\
231\end{array}$ & $\begin{array}{r}6,8 \\
-5,1 \\
-2,1 \\
-2,1 \\
-1,7\end{array}$ & $\begin{array}{l}38,4 \\
36,3 \\
36,8 \\
37,8 \\
37,8 \\
38,0\end{array}$ & $\begin{array}{r}-5,5 \\
-4,2 \\
-1,6 \\
-1,6 \\
-1,0\end{array}$ \\
\hline 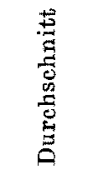 & $\begin{array}{r}\text { vor } \\
48 \\
96 \\
144 \\
192 \\
240\end{array}$ & $\begin{array}{l}1,5 \\
3,7 \\
5,4 \\
7,0 \\
8,4\end{array}$ & $\begin{array}{r}15,62 \\
15,43 \\
15,24 \\
15,05 \\
14,89 \\
14,78\end{array}$ & $\begin{array}{l}-1,3 \\
-2,4 \\
-3,7 \\
-4,6 \\
-5,3\end{array}$ & $\begin{array}{l}5,87 \\
5,78 \\
5,81 \\
5,83 \\
5,83 \\
5,84\end{array}$ & $\begin{array}{r}-1,4 \\
-1,0 \\
-0,6 \\
-0,6 \\
-0,4\end{array}$ & $\begin{array}{l}234 \\
217 \\
218 \\
225 \\
225 \\
227\end{array}$ & $\begin{array}{r}-7,2 \\
-6,3 \\
-3,7 \\
-3,7 \\
-3,0\end{array}$ & $\begin{array}{l}39,9 \\
37,6 \\
37,7 \\
38,6 \\
38,6 \\
38,9\end{array}$ & $\begin{array}{r}-5,8 \\
-5,4 \\
-3,2 \\
-3,2 \\
-2,6\end{array}$ \\
\hline
\end{tabular}

Daraus kann ohne weiteres gefolgert werden, dass, wenn das Blut unter anderer Bedingung als in vorausgegangener Versuchsanordnung, d.h. dasjenige Blut, dessen $\mathrm{pH}$ von vornherein bestimmte Veränderung erfahren hat, aufbewahrt ist, irgendwelche Veränderungen, die von den bei Konservierung des normalen Blutes auftretenden abweichen, aufweisen muss. Aus dieser Überlegung wurden zuerst Versuche am Blut 
2.

azidotischen Kaninchenblut.

\begin{tabular}{|c|c|c|c|c|c|c|}
\hline \multicolumn{2}{|c|}{ Serum-NaCl } & \multicolumn{2}{|c|}{ Blutzucker } & \multicolumn{2}{|c|}{ Blutmilchsäure } & \multirow[b]{2}{*}{ Bemerkungen } \\
\hline $\mathrm{mg} / \mathrm{dl}$ & 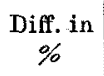 & $\mathrm{mg} / \mathrm{dl}$ & $\begin{array}{c}\text { Diff. in } \\
\%\end{array}$ & $\mathrm{mg} / \mathrm{dl}$ & $\begin{array}{c}\text { Diff. in } \\
\%\end{array}$ & \\
\hline $\begin{array}{l}570 \\
565 \\
565 \\
565 \\
565 \\
565\end{array}$ & $\begin{array}{l}-0,8 \\
-0,8 \\
-0,8 \\
-0,8 \\
-0,8\end{array}$ & $\begin{array}{l}97 \\
84 \\
74 \\
68 \\
59 \\
50\end{array}$ & $\begin{array}{l}-13,4 \\
-23,7 \\
-29,9 \\
-39,2 \\
-48,4\end{array}$ & $\begin{array}{l}36,64 \\
40,50 \\
45,00 \\
50,76 \\
55,29 \\
59,14\end{array}$ & $\begin{array}{r}+10,5 \\
+22,8 \\
+38,5 \\
+50,9 \\
+61,4\end{array}$ & $\begin{array}{l}\mathrm{pH} \text { vor } \mathrm{NH}_{4} \mathrm{Cl}-\mathrm{Gabe} 7,39 \\
\text { pH nach } \mathrm{NH}_{4} \mathrm{Cl} \text {-Gabe } 7,34\end{array}$ \\
\hline $\begin{array}{l}600 \\
590 \\
590 \\
590 \\
595 \\
595\end{array}$ & $\begin{array}{l}-1,6 \\
-1,6 \\
-1,6 \\
-0,8 \\
-0,8\end{array}$ & $\begin{array}{r}145 \\
132 \\
115 \\
106 \\
92 \\
75\end{array}$ & $\begin{array}{l}-9,0 \\
-20,7 \\
-26,9 \\
-36,5 \\
-48,3\end{array}$ & $\begin{array}{l}37,93 \\
42,43 \\
47,57 \\
53,36 \\
59,79 \\
64,29\end{array}$ & $\begin{array}{r}+11,9 \\
+25,4 \\
+40,7 \\
+57,6 \\
+69,5\end{array}$ & $\begin{array}{l}\mathrm{pH} \text { vor } \mathrm{NH}_{4} \mathrm{Cl}-\mathrm{Gabe} 7,37 \\
\mathrm{pH} \text { nach } \mathrm{NH}_{4} \mathrm{Cl}-\mathrm{Gab} \in 7,34\end{array}$ \\
\hline $\begin{array}{l}610 \\
605 \\
605 \\
605 \\
605 \\
605\end{array}$ & $\begin{array}{l}-0,8 \\
-0,8 \\
-0,8 \\
-0,8 \\
-0,8\end{array}$ & $\begin{array}{r}138 \\
124 \\
115 \\
106 \\
99 \\
86\end{array}$ & $\begin{array}{l}-10,1 \\
-16,7 \\
-23,2 \\
-28,3 \\
-37,6\end{array}$ & $\begin{array}{l}31,50 \\
34,71 \\
39,86 \\
44,36 \\
45,64 \\
49,50\end{array}$ & $\begin{array}{r}+10,2 \\
+26,5 \\
+40,8 \\
+44,9 \\
+57,1\end{array}$ & $\begin{array}{l}\text { pH vor } \mathrm{NH}_{4} \mathrm{Cl}-\mathrm{Gabe} 7,37 \\
\text { pH nach } \mathrm{NH}_{4} \mathrm{Cl} \text {-Gabe } 7,32\end{array}$ \\
\hline $\begin{array}{l}615 \\
605 \\
605 \\
605 \\
610 \\
610\end{array}$ & $\begin{array}{l}-1,6 \\
-1,6 \\
-1,6 \\
-0,8 \\
-0,8\end{array}$ & $\begin{array}{r}141 \\
127 \\
117 \\
108 \\
95 \\
86\end{array}$ & $\begin{array}{l}-9,9 \\
-17,0 \\
-23,3 \\
-32,6 \\
-39,1\end{array}$ & $\begin{array}{l}32,14 \\
36,00 \\
39,21 \\
44,36 \\
48,21 \\
52,71\end{array}$ & $\begin{array}{r}+12,0 \\
+22,0 \\
+38,0 \\
+50,0 \\
+64,0\end{array}$ & $\begin{array}{l}\mathrm{pH} \text { vor } \mathrm{NH}_{4} \mathrm{Cl} \text {-Gabe } 7,36 \\
\mathrm{pH} \text { nach } \mathrm{NH}_{4} \mathrm{Cl} \text {-Gabe } 7,30\end{array}$ \\
\hline $\begin{array}{l}550 \\
540 \\
540 \\
545 \\
545 \\
545\end{array}$ & $\begin{array}{l}-1,8 \\
-1,8 \\
-0,9 \\
-0,9 \\
-0,9\end{array}$ & $\begin{array}{r}101 \\
92 \\
86 \\
77 \\
70 \\
61\end{array}$ & $\begin{array}{r}-8,9 \\
-14,8 \\
-23,8 \\
-30,6 \\
-39,6\end{array}$ & $\begin{array}{l}28,93 \\
32,79 \\
37,29 \\
39,86 \\
42,43 \\
44,36\end{array}$ & $\begin{array}{r}+13,3 \\
+28,9 \\
+37,8 \\
+46,7 \\
+53,3\end{array}$ & $\begin{array}{l}\mathrm{pH} \text { vor } \mathrm{NH}_{4} \mathrm{Cl} \text {-Gabe } 7,38 \\
\mathrm{pH} \text { nach } \mathrm{NH}_{4} \mathrm{Cl} \text {-Gabe } 7,34\end{array}$ \\
\hline $\begin{array}{l}589 \\
581 \\
581 \\
582 \\
584 \\
584\end{array}$ & $\begin{array}{l}-1,3 \\
-1,3 \\
-1,1 \\
-0,8 \\
-0,8\end{array}$ & $\begin{array}{r}124 \\
112 \\
101 \\
93 \\
83 \\
72\end{array}$ & $\begin{array}{r}-10,3 \\
-18,6 \\
-25,4 \\
-33,4 \\
-42,6\end{array}$ & $\begin{array}{l}33,43 \\
37,29 \\
41,79 \\
46,54 \\
50,27 \\
54,00\end{array}$ & $\begin{array}{l}+11,6 \\
+25,1 \\
+39,2 \\
+50,0 \\
+61,1\end{array}$ & $\begin{array}{l}\mathrm{pH} \text { vor } \mathrm{NH}_{4} \mathrm{Cl} \text {-Gabe } 7,37 \\
\text { pH nach } \mathrm{NH}_{4} \mathrm{Cl} \text {-Gabe } 7,33\end{array}$ \\
\hline
\end{tabular}

des experimentell azidotisch gemachten Kaninchens angestellt. Hierbei wurde die Azidose mild und schwach erzeugt.

Es wurde nämlich einem normalen Kaninchen von 1,9-2,2 kg Körpergewicht morgens nüchtern eine 5\%ige Lösung von Ammoniumchlorid in Mengen von $3 \mathrm{ccm}$ pro $\mathrm{kg}$ Körpergewicht intravenös verabreicht. Diese Prozedur wurde jeden Tag wiederholt, und am dritten 
Fig. 1. Bestimmungen am normalen Kaninchenblut. (Durchschnittswerte)

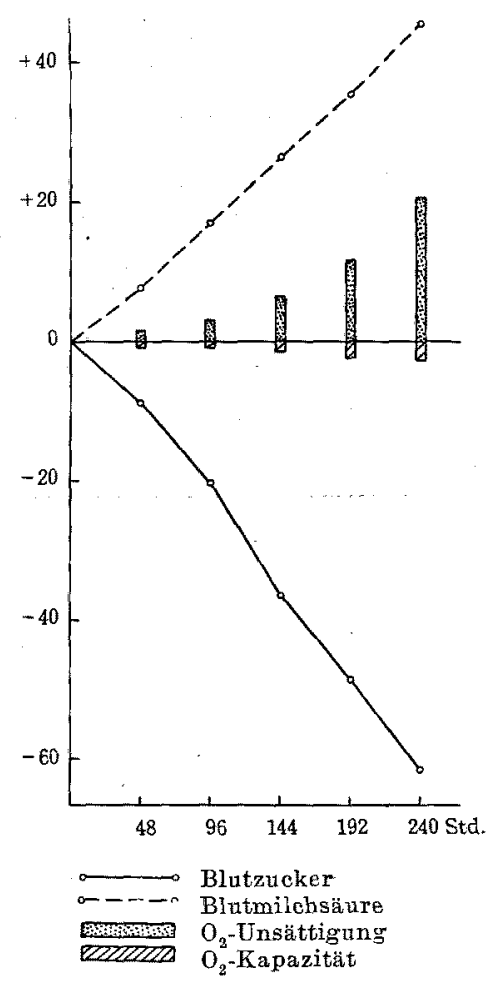

Fig. 2. Bestimmungen am azidotischem Kaninchenblut. (Durchschnittswerte)

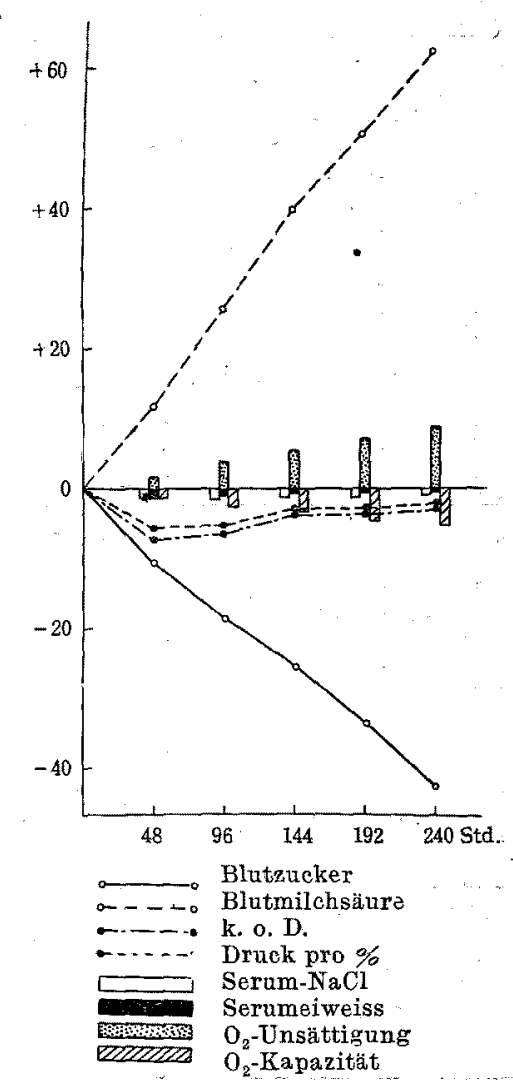

Tag derInjektion wurde 10Minuten post injectionem die Blutentnahme vorgenommen, an diesem Blut wurde Versuch ausgeführt. Die hier eingetretene Azidose war von schwachem Grade. Wie aus Tab. 2 ersichtlich, wurde z.B. pH des Blutes in Versuch 1 von 7,39 auf 7,34 ; in Versuch 4 von 7,36 auf 7,30 herabgesetzt.

$\mathrm{Zu}$ Messungen von Blut-pH wurde der Mislowitzer's Potensiometer benutzt, wobei die Chinhydronelektrode in Form der Mislowitzer's Spritze in der Modifikation von Nakaza wa und Sa to ${ }^{36)}$ verwendet wurde (Tab. 2 und Fig. 2).

36) Sato, Tohoku Journ. Exp. Med., 1931-32, 18, 576. 
$\mathrm{O}_{2}-$ Verbrauch: Der $\mathrm{O}_{2}$-Verbrauch der Erythrozyten vollzog sich in der ersten Hälfte der Aufbewahrungsdauer, d.h. bis zum 5.-6. Tag im annähend normalen Grad, von dẹr zweiten Hälfte an ging er nicht so intensiv vonstatten, so dass nach 10 Tagen nur 5,4-10,6\%, im Durchschnitt nur $8,4 \%$ des anfänglichen $\mathrm{O}_{2}$-Gehaltes verbraucht wurden. Diese Zifferzahl war dem normalen Blut gegenüber ausserordentlich verringert. $\mathrm{O}_{2}$-Kapazität des Blutes war mit dem Zeitablauf zur Herabsetzung geneigt, nach 10 Tagen wurde eine Abnahme von 3,5-7,7\%, durchschnittlich 5,3\% angetroffen, die grösser als in der Norm war. Es hat sich also herausgestellt, dass die Lebensfähigkeit der Erythrozyten bei der Azidosis herabgesetzt ist.

Serumeiweiss und k. o.D.: Zeitliche Verfolgung der Konzentrationsänderung des Serumeiweisses ergab, dass es in der Aufbewahrungsdauer von $48 \mathrm{bzw}$. 96 Std. stets eine, wenn auch geringfügige Verminderung erfuhr. Nach dieser Zeit kam das Serumeiweiss entweder zum Anfangswert zurück, oder beharrte bei vermindertem Wert. Auch der k. o. D. wurde nach Ablauf von 48-96 Std. deutlich erniedrigt gefunden, von dieser Zeit an rückte er mit dem Zeitablauf mehr oder minder an das Anfangsniveau heran, erreichte dennoch dasselbe nicht. Immerhin erfolgte die Erniedrigung des k. o. D. deutlicher als die Abnahme des Eiweisses. Mithin sank Druck pro \% im Ablauf von 48-96 Std. auffallend, so dass er selbst nach 240 Std. zum Anfangswert nicht wieder zurückkam.

Nach dem oben erwähnten Ergebnis erfährt das Serumeiweiss bei 48-96stündiger Aufbewahrung unverkennbar eine geringfügige Abnahme. Die Tatsache, dass hierbei eine weitgehend stärkere Erniedrigung des k. o. D. mit der Konsequenz der Herabsetzung des Drucks pro \% auftritt, spricht offenbar dafür, dass am Serumeiweiss nicht allein quantitative, sondern auch qualitative Veründerungen sich abspielen, daraus kann also ohne weiteres geschlossen werden, dass die Molekularaggregate des Bluteiweisses nach grob disperser Seite hin verschoben worden sind.

Serum-NaCl. Dieser Blutbestandteil erfuhr durch Aufbewahrung eine Abnahme, die allerdings mit einem Prozentsatz von 0,8-$1,8 \%$ zwar geringgradig, dennoch ohne Ausnahme erfolgte und zudem in 48stündiger Aufbewahrungsdauer nach meistens 0,8-1,8\%, im Mittel 1,3\% betrug oder um ein Geringes verringert war. Darnach scheint das Serum- $\mathbf{N a C l}$ im azidotischen Blut in den ersten Stunden der Aufbewahrung mehr oder weniger abzunehmen und zumeist bei der verringerten Konzentration zu beharren. 
Blutzucker und Blutmilchsäure: Während der Blutzucker im normalen Blut einen Wert von 81-120 mg/dl, durchschnittlich 102 $\mathrm{mg} / \mathrm{dl}$ aufgewiesen hatte, wurde er im azidotischen Blut zu einem Wert von $97-145 \mathrm{mg} / \mathrm{dl}$, im Mittel von $124 \mathrm{mg} / \mathrm{dl}$ ermittelt; durch Azidosis erfuhr er also eine Erhöhung. Was glykolytische Vorgänge des Blutes anbelangt, erfolgte die Blutzuckerabnahme bis zu den ersten $48-96$ Stunden nicht so sehr verschieden von der Norm; von diesem Zeitpunkt an aber nicht so rasch wie im normalen Blut, weshalb die Glykolyse in der zweiten Hälfte der Aufbewahrung der Norm gegenüber gewissermassen verzögert war. Die Zuckerabnahme in der Aufbewahrungsdauer von 240 Std. betrug nämlich dem Anfangswert gegenüber 37,648,4\%, im Mittel 42,6\%; im Vergleich mit einer Abnahme von 48,4$70,4 \%$, durchschnittlich $61,5 \%$ in der Norm war also die eben angeführte Abnahme ziemlich geringfügig. Da im azidotischen Blut der Blutzucker schon vom Anfang an höhere Werte aufwies, war die Zuckerabnahme, auch dem absoluten Wert nach, der Norm gegenüber geringfügig. Demnach scheint die Glykolyse durch Azidosis einigermassen gehemmt zu werden.

Auch die Blutmilchsäure schien scheinbar mehr oder weniger höhere Werte als beim Normalen aufzuweisen, bei näherer Betrachtung an den einzelnen Fällen ergab sich jedoch, dass das nicht immer derFall war. Jedenfalls lässt sich also sagen, dass die Milchsäure im ganzen genommen innerhalb der normalen Schwankungsbreite liegt. Die Zunahme der Milchsäure, welche mit Zuckerabnahme einherging, vollzog sich rascher als in der Norm und zwar derart, dass die Milchsäure nach 24 Std. der Aufbewahrung eine prozentische Zunahme von $53,3-69,5 \%$, durchschnittlich $61,1 \%$ aufwies, eine Zunahme, welche im allgemeinen grösser war als die Zunahme von 27,7-59,0\%, im Mittel 45,4\% in der Norm.

Die hier entrollte Tatsache, dass während die Abnahme des Zukkers, also die Glykolyse in etwas geringerem Masse als in der Norm statfand, die Milchsäure, ein Produkt der Glykolyse in höherem Grad als normal erfolgte, fällt uns auf den ersten Blick ziemlich befremdend auf, und die Erklärung dafür fällt uns vorderhand sehr schwer. Diese scheinbar widerspruchsvolle at Tatsache könnte sich dennoch erklären lassen, wenn man sich folgendermassen vorstellt: Wenn die Glykolyse im normalen Blut sich vollzieht, wird der Zucker, über die Zwischenprodukte, bei unzureichendem Oxydationsprozesse in die Milchsäure, aber bei hinreichender Oxydation endlich in $\mathrm{CO}_{2}$ und $\mathrm{H}_{2} \mathrm{O}$ gespalten, wobei ein Anteil des Zuckers entweder als Substanzen der Zwischen- 
stufe im Blut verbleibt oder durch Sauerstoff in $\mathrm{CO}_{2}$ und $\mathrm{H}_{2} \mathrm{O}$ umgewandelt wird; es geht der gespaltene Zuckeranteil keineswegs zur Gänze in die Milchsäure über.

Bei der Azidosis hingegen dürfte der Zuckeranteil, welcher sich durch oxydative Spaltung entweder zuerst in intermediäre Produkte ubbergeht und als solche verbleibt oder in $\mathrm{CO}_{2}$ und $\mathrm{H}_{2} \mathrm{O}$ umgewandelt wird, sich verringern, wogegen derjenige Anteil, der in die Milchsäure gespalten wird, überwiegen mag. Bei der Azidosis ist allenfalls die Oxydation des Blutes gehemmt, was sich auch durch die Erniedrigung der $\mathrm{O}_{2}$-Dissoziationskurve verrät.

Kurzum, im azidotischen Blut ist der $\mathrm{O}_{2}$-Verbrauch der Erythrozyten herabgesetzt, und bei Aufbewahrung desselben nimmt die $\mathrm{O}_{2}$ Kapazität ab. Dass bei Azidose der $\mathrm{O}_{2}$-Verbrauch vermindert ist, ist bereits von Chvostec, ${ }^{37}$ ) Loewy u. Münzer, ${ }^{38}$ Koehler u. Raymond, ${ }^{39)}$ It ${ }^{40)}{ }^{40} \mathrm{Kon}$ is h ${ }^{4},{ }^{41)}$ Ha manaka $a^{42)}$ u.a. erkannt worden. Die Herabsetzung der $\mathrm{O}_{2}$-Kapazität ist, wie oben geschildert, offenbar auf die Abnahme des $\mathrm{pH}$ zurückzuführen.

Das Eiweiss des Blutserums nimmt in den ersten Stadien der Aufbewahrung $a b$, nähert sich nachher dem Ursprungswert, ohne jedoch denselben je erreicht zu haben. K. o. D. erniedrigt sich viel deutlicher als die Eiweissabnahme. Mithin senkt sich Druck pro \% ausgesprochen. Das oben angeführte Verhalten des Blutserums deutet also darauf hin, das Eiweiss des Blutserums quantitativ ein wenig abnimmt, in qualitativer Hinsicht aber die Eiweissteilchen mit grösseren Molekularaggregaten relativ zunehmen. Da alles, was oben geschildert worden ist, sich im geschlossenen Medium abspielt, so soll sich bei der Abnahme der Serumeiweisskonzentration der Abtransport des Eiweisses auf das Innere der Erythrozyten beschränken. Dies dürfte wahrscheinlich daran liegen, dass ein Teil der kleineren mehr osmoaktiven Eiweissteilchen des Serums in die in ihrer Permeabilität gesteigerten Erythrozyten übergegangen ist.

Auch $\mathrm{NaCl}$ scheint gewissermassen aus dem Serum in die Blutzellen uberzugehen.

Die Vermehrung des Erythrozytenvolumens bei Azidose ist von

37) Chvostec, Centralbl. f. klin. Med., 1893, 14, 329.

38) Loew $y$. Mu un zer, Biochem. Ztschr., 1923, 134, 437.

39) Ko ehler u. Ra y m ond, Journ. Biol. Chem., 1925, 64, 739.

40) I to, Tohoku Journ. Exp. Med., 1926-27, 8, 75.

41) Konishi, Nippon Naikagakkai Zassi, 1981-32, 19, 707,

42) H a m a na ka, Mitteil. aus der Med. Akad. 2u Kiotc, 1936, 18, 1. 
Ege ${ }^{43)}$ Mori, ${ }^{44)}$ erwiesen worden. Nach Untersuchungen von $\mathrm{O}$ is $\mathbf{i}^{45)}$ an hiesiger Klinik müssen sicherlich in den Erythrozyten 6mal so viel Eiweisskörper, insbesondere das Albumin. als die Eiweisskörper im Plasma enthalten sein. Wenn das zuvor azidotisch gemachte Blut längere Zeit aufbewahrt wird, treten die Veränderungen von $\mathrm{pH}$ in weitaus stärkerem Grad als im normalen Blut zutage; es dürfte sich also hierbei höchstwahrscheinlich um eine Vergrösserung des Erythrozytenvolumens durch die Quellung des in den Erythrozyten enthaItenen Eiweisses handeln, wobei auch ausserdem das Eiweiss und $\mathrm{NaCl}$ samt dern Wasser vom Serum in die Erythrozyten übergehen dürften.

Die Erniedrigung des Drucks pro \% des Serumeiweisses ist wahrscheinlich ein Beweis dafür, dass kleine, osmoaktive Eiweissteilchen verhältnismässig mehr in die Erythrozyten übergegangen sind. Ferner muss man bei den Veränderungen der Eiweissfraktionen im Serum der eventuellen Umwandlung des Albumins ins Globulin im Seruminnein Rechnung tragen. Von Moll, ${ }^{46)} \mathrm{Rusznyák,{ } ^ { 4 7 } )} \mathrm{Ozawa}^{48)}$ ist bereits darauf hingewiesen worden, dass unter Einwirkungen von Säuren, Alkalien oder Wärme und dgl. im Serum, auch in vitro, die Verschiebung der Eiweissfraktionen zustande kommt.

Obwohl die Glykolyse im azidotischen Blut anscheinend in geringerem Grad als in der Norm vor sich geht, ist die Milchsäurebildung, aus oben angeführten Gründen, im Verhältnis zur Glykolyse gross. Der Blutzuckerspiegel bei der Azidose ist gewissermassen höher als in der Norm, was damit in Einklang steht, dass seitdem $\mathrm{Na}$ u $\mathrm{y} \mathrm{n}^{{ }^{49} \text { ) als }}$ erster bei der Azidose das Auftreten der Glykosurie fand, dieselbe von Sat ${ }^{50)}$ Ozawa, Aikawa u. Arakawa, ${ }^{51}$ Fujie u. Tsunet ${ }^{52}$. u.a. übereinstimmend erkannt worden ist.

\section{Versuch am alkalotischen Blut.}

Demnächst wurde Versuch am Blut mit verminderter Wasserstoffionenkonzentration, also am alkalotischen Blut durchgeführt. Das

43) Ege, Biochem. Ztschr., 1922, 130, 136.

44) Mori, Zikken Shokakibyogaku, 1929, 4, 589.

45) O i s i, Nippon Naikagakkai Zassi, 1937-38, 25, 428.

46) Mo 11, Hofmeister's Beitrage z. chem. Physiol. u. Path., 1904, 4, 563.

47) Ruszny $x_{k}$, Biochem. Ztschr., 1923, 140, I79.

48) Oz a wa, Eukuoka Ikadaigaku Zassi, 1926, 19, 701.

49) Na un y n, Nothnagel's Handbuch, Wien 1900, 7, 1. Hälfte.

50) Sato, Nippon Naikagakkai Zassi, 1921-22, 9, 136.

51) Ozawa, A ikawa u. A rakawa, Ibid., 1921-22, 9, 139.

52) Fujie u. Tsuneto, Chugai Ijisimpo, 1925, 767. 
Verfahren bestand darin, dass man einem normalen Kaninchen von 1,8$2,0 \mathrm{~kg}$ Körpergewicht morgens nüchtern $3 \mathrm{~g}$. Natrium bicarbona port kg Körpergewicht in $20 \mathrm{ccm}$ Aq. dest. gelöst, mittels Schlundsonde in den Magen einführte. Nach dreitägiger Verabreichung wurde 30 Minuten nach letzter Darreichung das Blut entnommen und zum Versuch benutzt. Nach obiger Behandlung wurde das $\mathrm{pH}$ des Blutes deutlich nach alkalotischer Seite hin verschoben. Es wurde z.B. pH von 7,37 auf $7,44, \mathrm{pH}$ von 7,39 auf 7,47 erhöht. Die Versuchsresultate sind in Tab. 3 zusammengestellt. Fig. 3 gibt prozentische $A b$ - und Zunahmen in Durchschnittswerten an.

$\mathrm{O}_{2}$-Verbrauch: Der $\mathrm{O}_{2}$-Verbrauch während der Aufbewahrungsdauer war im ganzen genommen deutlich kleiner als in der Norm. Im Fergleich mit demselben bei Azidosis war er aber, auch den einzelnenZiffern nach, einigermassen gross. Der $\mathrm{O}_{2}-$ Verbrauch im Ablauf von 240 Std. betrug nämlich 9,6-14,1\%, im Mittel 11,7\% des Anfangswertes. Die Abnahme der $\mathrm{O}_{2}$-Kapazität in 240-stündiger Aufbewahrungsdauer betrug 1,2-2,5\%, im Durchschnitt 2,0\%. Diese Zifferzahl war deutlich kleiner als bei der Azidosis. Gegenüber der Norm zeigte sie, den einzelnen Ziffern nach, keinen grossen Unterschied. Daraus ist also zu ersehen, dass im alkalotischen Blut der $\mathrm{O}_{2}$-Verbrauch gegenüber der Norm herabgesetzt ist, während die Abnahme der $\mathrm{O}_{2}$ Kapazität im grossen und ganzen im Bereich des Normalen liegt.

Serumeiweiss und k. o.D.: Serumeiweiss zeigte zwar geringe Schwankungen, doch kein eindeutiges Bild in bezug auf die $\mathrm{Ab}$ - und Zunahme. K. o. D. zeigte in den ersten Stadien der Aufbewahrung meistens mehr oder weniger Erniedrigung und kam in der zweiten Hälfte der Aufbewahrung gewissermassen zum Ursprungswert zurück, ohne jedoch denselben vollkommen erreicht zu haben. Diese Erniedrigung war zwar geringgradig, darf dennoch deshalb keineswegs ausser Acht gelassen werden, weil sie stets ohne einen einzigen Ausnahmefall erfolgte. Da, während das Serumeiweiss nicht so erhebliche Veräriderung erfuhr, der k. o. D. ohne Ausnahme eine Erniedrigung aufwies, sank Druck pro \% deutlich ab, der Abnahme des k. o. D. beinahe parallel gehend.

Serum-NaCl : Hier erfolgte eine, wenn auch geringgradige $\mathrm{Ab}-$ nahme ohne Ausnahme. Die prozentische Abnahme betrug 1,0-2,0\%, welche Abnahme im ersten oder mittleren Stadium der Aufbewahrung angetroffen wurde.

Blutzucker und Blutmilchsäure: Der Blutzuckerspiegel schien bei der Alkalosis mehr'oder weniger höher zu sein, aber nicht so 
Tabelle

Bestimmungen am

\begin{tabular}{|c|c|c|c|c|c|c|c|c|c|c|}
\hline \multirow{2}{*}{$\begin{array}{l}\text { Blut- } \\
\mathrm{Nr} \text {. }\end{array}$} & \multirow{2}{*}{$\begin{array}{c}\text { Zeit- } \\
\text { ablauf } \\
\text { Std. }\end{array}$} & \multirow{2}{*}{$\begin{array}{c}\mathrm{O}_{2} \text {-Un- } \\
\text { sätti- } \\
\text { gung } \\
0_{0}^{\prime}\end{array}$} & \multicolumn{2}{|c|}{$\mathrm{O}_{2}$-Kapazität } & \multicolumn{2}{|c|}{ Serumeiweiss } & \multicolumn{2}{|c|}{ K.o.D. } & \multicolumn{2}{|c|}{ Druek pro $\%$} \\
\hline & & & $\left|\begin{array}{c}\operatorname{cem} \text { in } \\
100 \\
\mathrm{ecm}\end{array}\right|$ & $\begin{array}{c}\text { Diff. in } \\
\%\end{array}$ & $\%$ & $\begin{array}{c}\text { Diff, in } \\
\%\end{array}$ & $\begin{array}{l}\mathrm{mm} \\
\mathrm{H}_{2} \mathrm{O}\end{array}$ & $\begin{array}{c}\text { Diff. in } \\
\% .\end{array}$ & $\begin{array}{l}m m \\
\mathrm{H}_{\mathrm{a}} \mathrm{O}\end{array}$ & $\begin{array}{c}\text { Diff. in } \\
\%\end{array}$ \\
\hline 1 & $\begin{array}{r}\text { vor } \\
48 \\
96 \\
144 \\
192 \\
240\end{array}$ & $\begin{array}{r}0,9 \\
2,3 \\
4,2 \\
7,5 \\
14,1\end{array}$ & $\begin{array}{l}18,04 \\
18,00 \\
17,97 \\
17,87 \\
17,65 \\
17,58\end{array}$ & $\begin{array}{l}-0,2 \\
-0,4 \\
-0,9 \\
-2,2 \\
-2,5\end{array}$ & $\begin{array}{l}5,60 \\
5,58 \\
5,58 \\
5,60 \\
5,60 \\
5,60\end{array}$ & $\begin{array}{l}-0,3 \\
-0,3 \\
\pm 0 \\
\pm 0 \\
\pm 0\end{array}$ & $\begin{array}{l}213 \\
203 \\
205 \\
210 \\
210 \\
210\end{array}$ & $\begin{array}{r}-4,7 \\
-3,7 \\
-1,4 \\
-1,4 \\
-1,4\end{array}$ & $\begin{array}{l}38,0 \\
36,4 \\
36,7 \\
37,5 \\
37,5 \\
37,5\end{array}$ & $\begin{array}{r}-4,2 \\
-3,4 \\
-1,3 \\
-1,3 \\
-1,3\end{array}$ \\
\hline 2 & $\begin{array}{r}\text { vor } \\
48 \\
96 \\
144 \\
192 \\
240\end{array}$ & $\begin{array}{r}0,4 \\
1,3 \\
4,4 \\
5,7 \\
10,9\end{array}$ & $\begin{array}{l}19,42 \\
19,40 \\
19,36 \\
19,27 \\
19,29 \\
19,19\end{array}$ & $\begin{array}{l}-0,1 \\
-0,3 \\
-0,8 \\
-1,0 \\
-1,2\end{array}$ & $\begin{array}{l}5,47 \\
5,47 \\
5,47 \\
5,47 \\
5,47 \\
5,47\end{array}$ & $\begin{array}{l} \pm 0 \\
\pm 0 \\
\pm 0 \\
\pm 0 \\
\pm 0\end{array}$ & $\begin{array}{l}225 \\
220 \\
223 \\
223 \\
223 \\
223\end{array}$ & $\begin{array}{r}-2,2 \\
-0,9 \\
-0,9 \\
-0,9 \\
-0,9\end{array}$ & $\begin{array}{l}41,1 \\
40,2 \\
40,8 \\
40,8 \\
40,8 \\
40,8\end{array}$ & $\begin{array}{r}-2,1 \\
-0,7 \\
-0,7 \\
-0,7 \\
-0,7\end{array}$ \\
\hline 8 & $\begin{array}{r}\text { vor } \\
48 \\
96 \\
144 \\
192 \\
240\end{array}$ & $\begin{array}{r}0,9 \\
1,9 \\
4,8 \\
7,8 \\
12,0\end{array}$ & $\begin{array}{l}17,61 \\
17,49 \\
17,41 \\
17,40 \\
17,34 \\
17,28\end{array}$ & $\begin{array}{l}-0,7 \\
-1,1 \\
-1,2 \\
-1,5 \\
-1,9\end{array}$ & $\begin{array}{l}5,75 \\
5,75 \\
5,72 \\
5,72 \\
5,75 \\
5,75\end{array}$ & $\begin{array}{l} \pm 0 \\
-0,5 \\
-0,5 \\
\pm 0 \\
\pm 0\end{array}$ & $\begin{array}{l}218 \\
218 \\
215 \\
215 \\
217 \\
217\end{array}$ & $\begin{array}{l} \pm 0 \\
-1,4 \\
-1,4 \\
-0,4 \\
-0,4\end{array}$ & $\begin{array}{l}37,9 \\
37,9 \\
37,6 \\
37,6 \\
37,7 \\
37,7\end{array}$ & $\begin{array}{l} \pm 0 \\
-0,8 \\
-0,8 \\
-0,5 \\
-0,5\end{array}$ \\
\hline 4 & $\begin{array}{r}\text { vor } \\
48 \\
96 \\
144 \\
192 \\
240\end{array}$ & $\begin{array}{r}1,0 \\
2,5 \\
5,2 \\
8,7 \\
12,0\end{array}$ & $\begin{array}{l}16,98 \\
16,91 \\
16,79 \\
16,78 \\
16,73 \\
16,59\end{array}$ & $\begin{array}{l}-0,4 \\
-1,1 \\
-1,2 \\
-1,5 \\
-2,3\end{array}$ & $\begin{array}{l}5,54 \\
5,54 \\
5,54 \\
5,51 \\
5,51 \\
5,54\end{array}$ & $\begin{array}{l} \pm 0 \\
\pm 0 \\
-0,5 \\
-0,5 \\
\pm 0\end{array}$ & $\begin{array}{l}208 \\
205 \\
205 \\
203 \\
203 \\
205\end{array}$ & $\begin{array}{l}-1,4 \\
-1,4 \\
-2,4 \\
-2,4 \\
-1,4\end{array}$ & $\begin{array}{l}37,5 \\
37,0 \\
37,0 \\
36,8 \\
36,8 \\
37,0\end{array}$ & $\begin{array}{r}-1,3 \\
-1,3 \\
-1,9 \\
-1,9 \\
-1,3\end{array}$ \\
\hline 5 & $\begin{array}{r}\text { จ } \\
48 \\
96 \\
144 \\
192 \\
240\end{array}$ & $\begin{array}{l}0,9 \\
1,8 \\
4,4 \\
7,8 \\
9,6\end{array}$ & $\begin{array}{l}18,68 \\
18,60 \\
18,54 \\
18,47 \\
18,39 \\
18,30\end{array}$ & $\begin{array}{l}-0,4 \\
-0,7 \\
-1,1 \\
-1,5 \\
-2,0\end{array}$ & $\begin{array}{l}5,58 \\
5,58 \\
5,56 \\
5,56 \\
5,56 \\
5,56\end{array}$ & $\begin{array}{l} \pm 0 \\
-0,3 \\
-0,3 \\
-0,3 \\
-0,3\end{array}$ & $\begin{array}{l}210 \\
208 \\
206 \\
206 \\
208 \\
208\end{array}$ & $\begin{array}{l}-0,9 \\
-1,9 \\
-1,9 \\
-0,9 \\
-0,9\end{array}$ & $\begin{array}{l}37,6 \\
37,3 \\
37,0 \\
37,0 \\
37,4 \\
37,4\end{array}$ & $\begin{array}{l}-0,8 \\
-1,5 \\
-1,5 \\
-0,5 \\
-0,5\end{array}$ \\
\hline 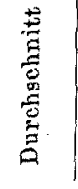 & $\begin{array}{r}\text { vor } \\
48 \\
96 \\
144 \\
192 \\
240\end{array}$ & $\begin{array}{r}0,8 \\
2,0 \\
4,6 \\
7,5 \\
11,7\end{array}$ & $\begin{array}{l}18,14 \\
18,08 \\
18,01 \\
17,96 \\
17,86 \\
17,78\end{array}$ & $\begin{array}{l}-0,4 \\
-0,7 \\
-1,0 \\
-1,5 \\
-2,0\end{array}$ & $\begin{array}{l}5,59 \\
5,58 \\
5,57 \\
5,57 \\
5,58 \\
5,58\end{array}$ & $\begin{array}{l}-0,1 \\
-0,2 \\
-0,2 \\
-0,1 \\
-0,1\end{array}$ & $\begin{array}{l}215 \\
211 \\
211 \\
211 \\
212 \\
213\end{array}$ & $\begin{array}{l}-1,8 \\
-1,8 \\
-1,8 \\
-1,2 \\
-1,0\end{array}$ & $\begin{array}{l}38,4 \\
37,8 \\
37,8 \\
37,9 \\
38,0 \\
38,1\end{array}$ & $\begin{array}{l}-1,7 \\
-1,7 \\
-1,2 \\
-1,0 \\
-0,9\end{array}$ \\
\hline
\end{tabular}

bemerkbar höher als in der Norm. Die mit dem Zeitablauf erfolgte Abnahme war grösser als bei der Azidosis und beinahe gleich gross wie in der Norm. Die Blutzuckerabnahme nämlich, welche in einer Aufbewahrungsdauer von $240 \mathrm{Std}$. zustande kam, betrug $65,8-70,0 \%$, im Durchschnitt 68,1\%.

Die Blutmilchsäure zeigte vor der Aufbewahrung im grossen und 
3.

alkalotischen Kaninchenblut.

\begin{tabular}{|c|c|c|c|c|c|c|}
\hline \multicolumn{2}{|c|}{ Serum-NaCl } & \multicolumn{2}{|c|}{ Blutzucker } & \multicolumn{2}{|c|}{ Blutmillchsäure } & \multirow[b]{2}{*}{ Bemerkungen } \\
\hline $\mathrm{mg} / \mathrm{dl}$ & $\underset{\%}{\text { Diff, in }}$ & $\mathrm{mg} / \mathrm{d} \mathrm{l}$ & $\begin{array}{c}\text { Diff, in } \\
\%\end{array}$ & $\mathrm{mg} / \mathrm{dl}$ & $\begin{array}{c}\text { Diff. in } \\
\%\end{array}$ & \\
\hline $\begin{array}{l}500 \\
490 \\
490 \\
495 \\
495 \\
495\end{array}$ & $\begin{array}{r}-2,0 \\
-2,0 \\
-1,0 \\
-1,0 \\
-1,0\end{array}$ & $\begin{array}{r}115 \\
101 \\
86 \\
66 \\
50 \\
36\end{array}$ & $\begin{array}{r}-12,2 \\
-25,2 \\
-42,6 \\
-56,5 \\
-68,7\end{array}$ & $\begin{array}{l}29,57 \\
32,14 \\
34,71 \\
36,64 \\
38,57 \\
40,50\end{array}$ & $\begin{array}{r}+8,7 \\
+17,4 \\
+23,9 \\
+30,4 \\
+37,0\end{array}$ & $\begin{array}{l}\text { pH vor } \mathrm{NaHCO}_{3} \text {-Gabe } 7,39 \\
\text { pH nach } \mathrm{NaHCO}_{3} \text { Gabe } 7,47\end{array}$ \\
\hline $\begin{array}{l}490 \\
490 \\
485 \\
485 \\
485 \\
485\end{array}$ & $\begin{array}{l} \pm 0 \\
-1,0 \\
-1,0 \\
-1,0 \\
-1,0\end{array}$ & $\begin{array}{r}122 \\
106 \\
90 \\
74 \\
57 \\
39\end{array}$ & $\begin{array}{l}-13,1 \\
-26,2 \\
-39,3 \\
-53,3 \\
-68,0\end{array}$ & $\begin{array}{l}31,50 \\
33,43 \\
36,00 \\
37,93 \\
39,86 \\
41,79\end{array}$ & $\begin{array}{l}+6,1 \\
+14,3 \\
+20,4 \\
+26,5 \\
+32,7\end{array}$ & $\begin{array}{l}\text { pH vor } \mathrm{NaHCO}_{3}-\mathrm{Gabe} 7,37 \\
\text { pH nach } \mathrm{NaHCO}_{3} \text {-Gabe } 7,44\end{array}$ \\
\hline $\begin{array}{l}510 \\
510 \\
500 \\
500 \\
500 \\
505\end{array}$ & $\begin{array}{l} \pm 0 \\
-1,9 \\
-1,9 \\
-1,9 \\
-0,9\end{array}$ & $\begin{array}{r}129 \\
115 \\
95 \\
79 \\
59 \\
39\end{array}$ & $\begin{array}{l}-10,8 \\
-26,3 \\
-38,7 \\
-54,3 \\
-70,0\end{array}$ & $\begin{array}{l}32,79 \\
35,36 \\
37,29 \\
39,21 \\
40,50 \\
43,07\end{array}$ & $\begin{array}{r}+7,8 \\
+13,7 \\
+19,6 \\
+23,5 \\
+31,3\end{array}$ & $\begin{array}{l}\text { pH vor } \mathrm{NaHCO}_{3}-\mathrm{Gabe} 7,39 \\
\text { pH nach } \mathrm{NaHCO}_{3} \text {-Gabe } 7,43\end{array}$ \\
\hline $\begin{array}{l}485 \\
480 \\
480 \\
480 \\
480 \\
480\end{array}$ & $\begin{array}{l}-1,0 \\
-1,0 \\
-1,0 \\
-1,0 \\
-1,0\end{array}$ & $\begin{array}{r}120 \\
102 \\
83 \\
68 \\
54 \\
41\end{array}$ & $\begin{array}{l}-15,0 \\
-30,8 \\
-43,3 \\
-55,0 \\
-65,8\end{array}$ & $\begin{array}{l}28,93 \\
31,50 \\
34,07 \\
37,29 \\
40,50 \\
42,43\end{array}$ & $\begin{array}{r}+8,9 \\
+17,8 \\
+28,9 \\
+40,0 \\
+46,7\end{array}$ & $\begin{array}{l}\mathrm{pH} \text { vor } \mathrm{NaHCO}_{3}-\mathrm{Gabe} 7,39 \\
\text { pH nach } \mathrm{NaHCO}_{3} \text {-Gabe } 7,44\end{array}$ \\
\hline $\begin{array}{l}480 \\
480 \\
470 \\
470 \\
475 \\
475\end{array}$ & $\begin{array}{l} \pm 0 \\
-2,0 \\
-2,0 \\
-1,0 \\
-1,0 .\end{array}$ & $\begin{array}{r}119 \\
102 \\
81 \\
61 \\
48 \\
38\end{array}$ & $\begin{array}{l}-14,3 \\
-31,9 \\
-48,7 \\
-59,7 \\
-68,1\end{array}$ & $\begin{array}{l}30,86 \\
32,14 \\
34,71 \\
37,29 \\
40,50 \\
43,07\end{array}$ & $\begin{array}{r}+4,1 \\
+12,5 \\
+20,8 \\
+31,2 \\
+39,6\end{array}$ & $\begin{array}{l}\text { pH vor } \mathrm{NaHCO}_{3}-\mathrm{Gabe} 7,39 \\
\text { pH nach } \mathrm{NaHCO}_{3}-\mathrm{Gabe} 7,43\end{array}$ \\
\hline $\begin{array}{l}493 \\
491 \\
485 \\
486 \\
487 \\
489\end{array}$ & $\begin{array}{l}-0,6 \\
-1,6 \\
-1,4 \\
-1,2 \\
-1,0\end{array}$ & $\begin{array}{r}121 \\
105 \\
87 \\
70 \\
54 \\
38\end{array}$ & $\begin{array}{l}-13,1 \\
-28,1 \\
-42,5 \\
-55,8 \\
-68,1\end{array}$ & $\begin{array}{l}30,73 \\
32,91 \\
35,36 \\
37,67 \\
39,99 \\
42,17\end{array}$ & $\begin{array}{r}+7,1 \\
+15,1 \\
+22,7 \\
+30,3 \\
+37,5\end{array}$ & $\begin{array}{l}\text { pH vor } \mathrm{NaHCO}_{3}-\mathrm{Gabe} 7,39 \\
\text { pH nach } \mathrm{NaHCO}_{3} \text {-Gabe } 7,44\end{array}$ \\
\hline
\end{tabular}

ganzen annähernd gleiche Werte, wie in der Norm und bei der Azidosis; gleichwohl ist hier bemerkenswert, dass die Zunahme der Milchsäure, welche mit dem Zeitablauf erfolgte, in einer Aufbewahrungsdauer von 240 Std. 31,3-46,7\%, im Durchschnitt 37,5\% ausmachte. Auch den einzelnen Zifferzahlen nach beurteilt, erwies sich die Zunahme der Milchsäure im allgemeinen in Vergleich sowohl mit der Norm, wie 
Fig. 3. Bestimmungen am alkalotischen Kaninchenblut.

(Durchschnittswerte)

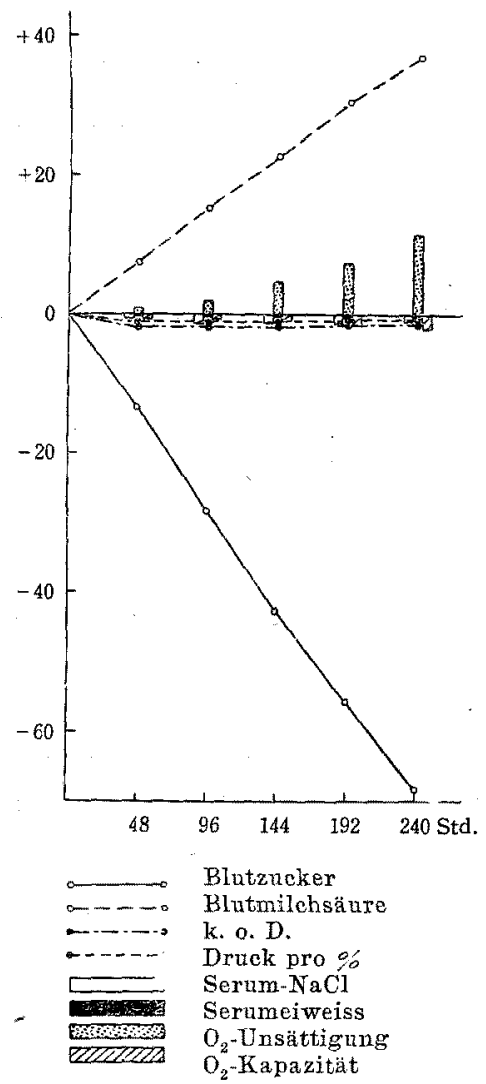

auch mit der Azidosis, als geringergradig als die Abnahme des Zuckers. Es dürfte dies wahrscheinlich dahin gedeutet werden, dass im alkalotischen Blut der Zuckeranteil, der bei der Zuckerspaltung durch Glykolyse nicht bis in die Milchsäure umgewandelt wird, sondern als deren Zwischenstufe verbleibt oder anderweitig verarbeitet wird, vermehrt ist.

Kurzum, auch im alkalotischen Blut vollzieht sich bei der Konservierung ein Eiweissaustausch zwischen Blutzellen und Serum. Aller Wahrscheinlichkeit nach dürften relativ kleinere Eiweissteilchen des Serums teilweise in die Blutzellen eintreten, wobei auch zugleich mehr oder weniger grössere Eiweissteilchen ein wenig aús den Zellen in das Serum mobilisiert werden. Anderseits aber scheint ein Teil des Serumeiweisses schon in vitro, wie oben im Abschnitt über die Azidosis angedeutet wurde, im Serum selbst eine Verschiebung der Eiweissfraktionen zu erleiden; indern das Albumin zum Teil ins

Globulin umgewandelt wird. Daraus folgt höchstwahrscheinlich, dass obwohl das Serumeiweiss an sich keine bemerkbare Mengenschwankungen aufweist, im Serum eine Verschiebung der Eiweissfraktionen nach grobdisperser Seite hin auftritt, wodurch relative Zunahme der grobmolekulären Eiweissteilchen stattfindet und somit Erniedrigungen des k.o.D. sowie Drucks pro \% zustande kommen. Auch das $\mathrm{NaCl}$ tritt, wenn auch in geringen Mengen, in die Blutzellen hinein. Zwar geht die Glykolyse in gleicher Intensität wie in der Norm vor sich, die Zunahme der Milchsäure ist aber im Vergleich zur Norm geringfügig. 


\section{Zusammenfassung.}

Es wurden normales sowie azidotisches bzw. alkalotisches Blut nach Defibrinierung 10 Tage lang im Eisschrank aufbewahrt. An jedem Blut wurden die Veränderungen des $\mathrm{O}_{2}$-Verbrauchs von Erythrozyten, der Serumeiweisskonzentration, des kolloid-osmotischen Drucks (k. o. D.), Serum-NaCl und der Glykolyse untersucht.

1. Im normalen Blut verbrauchten die Erythrozyten 14,7-27,6\%, im Durchschnitt 20,9\% des ursprünglichen $\mathrm{O}_{2}$-Gehaltes. Die $\mathrm{O}_{2}$ Kapazität des Blutes nimmt ein wenig ab. An Serumeiweiss, k. o. D. und Serum-NaCl sind keine erheblichen Veränderungen nachzuweisen. Die Glykolyse tritt deutlich zutage, und zwar derart, dass der Blutzucker um 48,4-70,4\%, im Mittel um 61,5\% des Anfangswertes vermindert ist; wogegen die Milchsäure eine Zunąhme von 27,7-59,0\%, durchschnittlich $45,4 \%$ erfährt.

2. Im azidotischen Blut ist der $\mathrm{O}_{2}$-Verbrauch der Erythrozyten der Norm gegenuiber herabgesetzt, wobei auch die Abnahme der $\mathrm{O}_{2}$ Kapazität grösser als im normalen Blut ist. Serumeiweiss nimmt ab, auch k. o. D. erniedrigt sich ; und da die Erniedrigung des letzteren stärker als die Abnahme des ersteren ist, sinkt Druck pro \%ab. Auch Serum-NaCl vermindert sich. Die Glykolyse geht der Norm gegenüber einigermassen verzögert vonstatten, die Zunahme der Milchsäure jedoch ist grösser als in der Norm.

3. Im alkalotischen Blut ist der $\mathrm{O}_{3}$-Verbrauch der Erythrozyten im Vergleich zur Norm herabgesetzt, die $\mathrm{O}_{2}$-Kapazität nimmt aber in annähernd gleichem Masse wie in der Norm ab. Da beim Ausbleiben der Abnahme des Serumeiweisses der k. o. D. sich um ein Geringes erniedrigt, sinkt Druck pro \% ab. Serum- $\mathrm{NaCl}$ erfährt eine Abnahme. Die Glykzolyse vollzieht sich ohne wesentliche Abweichung von der Norm, die Zunahme der Milchsäure ist indessen kleiner als in der Norm. 